\title{
SMALL-GROUP, COMPUTER-ASSISTED TUTORING TO IMPROVE READING OUTCOMES FOR STRUGGLING FIRST AND SECOND GRADERS
}

\begin{abstract}
A B S T RA C T
This study evaluated the relative effects of Tier II computer-assisted tutoring in small groups (Team Alphie) and one-to-one tutoring provided to struggling readers in 33 high-poverty Success for All (SFA) schools. In this year-long study, struggling readers in the Team Alphie schools were tutored in groups of 6 . In the control schools, students were tutored using the standard oneto-one tutoring process used in SFA. Analyses of covariance of students' standardized reading scores indicated that the first-grade treatment group significantly outperformed the control group on all 3 reading measures, with no significant differences for second graders. Schools using Team Alphie were able to tutor many more students than the control schools. This study shows that a computer-assisted, small-group tutoring program may be at least as effective as one-to-one tutoring and serve more struggling readers. It may serve as a good example of Tier II instruction in a response to intervention (RTI) model.
\end{abstract}

\author{
Bette Chambers \\ Robert E. Slavin \\ Nancy A. Madden \\ JOHNS HOPKINS \\ UNIVERSITY AND \\ UNIVERSITY OF YORK
}

Philip Abrami

CONCORDIA UNIVERSITY

Michele K. Logan

Richard Gifford

SUCCESS FOR ALL FOUNDATION

UCCESS in school is virtually synonymous with success in reading, and children who finish elementary school with weak reading skills are at a very high risk of dropping out before they finish high school. Children's reading failure in the early grades costs the education system and society a great deal, in special education, remediation, grade repetition, delinquency, and, ultimately, dropout. Reading failure is concentrated among schools serving many disadvan-

THE ELEMENTARY SCHOOL JOURNAL VOLUME 111, NUMBER 4

(C) 2011 by The University of Chicago. All rights reserved. 0013-5984/2011/11104-0007 \$10.00 
taged, minority, and limited-English-proficient children. It is in the early elementary grades where the gap in performance between children of different races first appears, and this gap is perhaps the most important policy issue in education in the United States.

On the fourth-grade National Assessment of Educational Progress (NAEP, 2007), $43 \%$ of white children achieved at the "proficient" level, but only $14 \%$ of African American, $17 \%$ of Hispanic, and $8 \%$ of American Indian children scored at this level. Effective reading programs are important for children of all backgrounds, but for disadvantaged and minority children who particularly depend on school to achieve success, effective reading programs are especially important. Because of the importance of ensuring success in reading for all children, it is especially important to evaluate promising programs that have potential for a strong and lasting impact on the reading success of struggling children. In particular, the widespread use of response to intervention (RTI) models has emphasized the use of small-group remedial interventions for children who have had difficulty in initial instruction (Fuchs \& Fuchs, 2006). This makes the development of small-group methods capable of helping struggling readers keep up with regular classroom instruction especially important.

This article describes the development and evaluation of an innovative intervention, called Team Alphie, that combines computer-assisted instruction and cooperative learning to help small groups of struggling beginning readers. Team Alphie is the second tier of an RTI model that has been developed over time by the Success for All Foundation in collaboration with the Center for Research and Reform in Education at Johns Hopkins University, the Centre for the Study of Learning and Performance at Concordia University in Montreal, and the Institute for Effective Education at the University of York in the United Kingdom. The first tier is the core reading instruction of the Success for All (SFA) comprehensive reform model, and the third tier is Alphie's Alley, a one-to-one, computer-assisted tutoring program for struggling readers.

Many different types of interventions have been designed to bring struggling readers up to grade level. One-to-one tutoring by certified teachers appears to be the most effective method, yet few schools can afford to tutor all students who experience difficulties in learning to read. A recent systematic review of interventions for struggling readers by Slavin, Lake, Davis, and Madden (2010) found phonetic oneto-one tutoring by certified teachers to be the most effective method for supporting struggling readers, with an average effect size of 0.69 . Yet tutoring by certified teachers is expensive, so several alternatives have been evaluated. One is tutoring by paraprofessionals. Slavin et al.'s (2010) review found that phonetic tutoring programs with paraprofessional tutors averaged an effect size of 0.38. A small study by Brown, Morris, and Fields (2005) that directly compared teachers and paraprofessionals as tutors using the same program also found higher effects for teachers $(E S=0.47)$. Similarly, Ehri, Dreyer, Flugman, and Gross (2007) found much better outcomes for teachers than for paraprofessionals using the same program $(E S=0.52)$. In both of these studies, certified teachers were far more effective, but students tutored by paraprofessionals still obtained much better outcomes than nontutored controls.

Another way that schools attempt to make tutoring more cost effective is to provide tutoring to small groups of children rather than one-to-one tutoring. Smallgroup tutorials with a focus on phonics can be effective but, again, are not as effective 
as one-to-one phonetically focused tutoring. Slavin, Lake, Chambers, Cheung, and Davis (2009) found a weighted mean effect size of 0.31 for small-group tutoring, which was less than for phonetic tutoring by certified teachers (mean $E S=0.69$ ) but similar to that for tutoring by paraprofessionals $(E S=0.38)$. A study using similar instructional methods directly compared one-to-one, one-to-three, and one-to-ten groupings for struggling second graders (Vaughn et al., 2003). Results for monolingual English students showed that one-to-one tutoring was moderately more effective than one-to-three tutoring $(E S=0.32)$ and considerably more effective than one-to-ten tutoring $(E S=0.71)$.

\section{Background}

\section{Technology in Beginning Literacy}

Educators have also turned to technology to help struggling readers. Computerassisted instruction (CAI) programs are easy to implement, adapt to children's specific needs, and provide activities with graphics that can supplement classroom instruction. CAI applications in early literacy have overwhelmingly consisted of individual students working through self-instructional materials geared to their level of performance. Typically these methods, such as Jostens/Compass Learning, Success Maker, and WICAT, have provided children with two or three 30-45-minute sessions a week. Because children perform at different levels, there is little if any link between what children do on the computer and what they do in reading class, and they rarely receive more than cursory reteaching when they run into difficulties. Because there may or may not be teachers available during tutoring time, traditional CAI activities in reading are typically designed to be relatively easy and repetitive. Much of teaching children to read requires hearing them read out loud, yet even the most advanced voice-recognition programs do not yet work with young readers. Perhaps for these reasons, research evaluating traditional computer-based instruction for reading has found few effects for struggling readers (Slavin et al., 2010) or for children in general (Kulik, 2003; Slavin, Lake, Chambers, et al., 2009). A large-scale randomized evaluation of five modern CAI programs found no effects on beginning reading measures either for students in general or for low achievers (Campuzano, Dynarski, Agodini, \& Rall, 2009; Dynarski et al., 2007).

\section{Research Base for Team Alphie}

Team Alphie, the small-group literacy intervention evaluated in this research, applies elements of CAI, embedded multimedia, and peer-assisted learning in an effort to create a Tier II small-group approach that is as effective as one-to-one tutoring for struggling readers. The following sections discuss the research base for the elements of Team Alphie.

While research provides far more support for all forms of one-to-one and smallgroup teaching than for traditional forms of CAI, there is a growing body of evidence that computers can help human teachers obtain better outcomes in early literacy. Computers can help teachers diagnose reading difficulties, individualize instruction, engage children's attention with dynamic activities, increase implementation fidelity (including through the use of embedded multimedia support for teachers and stu- 
dents), provide instant and consistent feedback, track children's progress, and provide ongoing reports for tutors and teachers (Klein, Nir-Gal, \& Darom, 2000).

Savage, Abrami, Hipps, and Deault (2009) have developed and carried out a randomized evaluation of ABRACADABRA - a Web-based, multimedia early literacy tool that promotes skills in alphabetics, fluency, comprehension, and writing. Unlike traditional CAI, ABRACADABRA is used in regular reading classes and is fully integrated with other teaching methods. Students work in four small groups per class. A 13-week evaluation showed statistically significant advantages for Canadian first graders who experienced the program on standardized measures of letter-sound knowledge, phonological blending, listening comprehension, and reading comprehension. Intervention effects for listening comprehension reflected one full stanine of improvement, and effects for phonological blending ability were even larger. Crucially, the effects were evident at a delayed posttest when children's reading was reassessed in grade 2, 8 months after the ABRACADABRA intervention had formally ended (Abrami et al., 2010; Abrami, Savage, Wade, Hipps, \& Lopez, 2008).

Chambers and her colleagues (Chambers, Abrami, et al., 2008; Chambers, Slavin, et al., 2008) developed and evaluated a computer-assisted tutoring program called Alphie's Alley. Within schools using the Success for All comprehensive reform model, tutors work one-to-one with first and second graders who are struggling to learn to read. Alphie's Alley adds computer activities, record keeping, and other activities to help tutors enhance the effectiveness of their tutoring. Alphie's Alley is described in more detail later in this article. What is important here is that two large randomized evaluations found that tutors who used the computer obtained better outcomes than did control tutors who taught using ordinary SFA tutoring strategies (Chambers, Abrami, et al., 2008; Chambers, Slavin, et al., 2008).

The positive effects seen in the Alphie's Alley studies raise an interesting possibility. Given the reality that most schools are not able to provide one-to-one tutoring for all of their struggling readers, it would be very beneficial to create approaches that are able to extend the effective principles of individual tutoring to small-group tutoring. Human tutors supplemented by computer software designed for this purpose may offer such a solution. The Success for All Foundation (SFAF), in collaboration with the Centre for the Study of Learning and Performance (CSLP) at Concordia University in Montreal, designed computer software intended to make it possible for paraprofessionals to effectively tutor small groups of struggling readers in Success for All schools. The result was Team Alphie, which adapts the one-to-one Alphie's Alley computer-assisted tutoring program to function in groups of up to six students. This article reports the findings of a large-scale randomized evaluation of Team Alphie.

\section{Success for All}

The present project took place within schools using the SFA comprehensive reform program, with children regrouped into classes of about 20 students of homogenous ability for the 90-minute reading block (Slavin, Madden, Chambers, \& Haxby, 2009). The first-tier instruction in this program is the beginning reading component of SFA, which focuses on phonemic awareness, letter-sound correspondence, wordlevel decoding, reading decodable stories, engaging in interactive book sharing, vocabulary, and writing activities. It makes extensive use of cooperative learning, a rapid pace of instruction, and frequent assessment. 
Most importantly for the present research, SFA provides daily tutoring for children in grades 1-3 who experience difficulties learning to read. More than 50 experimental-control comparison studies have evaluated the reading impacts of SFA and have found overall positive effects (Borman, Hewes, Overman, \& Brown, 2003; Comprehensive School Reform Quality Center, 2006; Slavin, Lake, et al., 2009). For example, a national longitudinal randomized evaluation involving 35 schools found positive effects of the program (Borman et al., 2007). Our study does not evaluate SFA, which was a constant in both treatment conditions, though SFA provided the context for the study. See Slavin, Madden, et al. (2009) for an overview of the SFA program and the underlying theoretical model.

Consistent with an RTI approach to providing extra support targeted at struggling readers, in SFA schools the lowest-achieving first-grade students in reading are assigned to receive one-to-one tutoring for 20 minutes each day. Schools are expected to tutor about $30 \%$ of their first graders, $20 \%$ of their second graders, and $10 \%$ of their third graders, depending on their tutoring resources. Tutors assess each student and determine individualized plans for instruction. They carry out these plans and engage in ongoing communication about the students' progress with their reading teachers. Tutors review the student's progress every 2 weeks, set goals, and adjust plans as needed.

For struggling readers, the tutoring sessions focus on the skills that the individual child needs to work on most. For struggling beginning readers, this is usually auditory blending and segmenting, letter-sound correspondence, and word-level blending. The students spend some time in each session practicing reading the decodable stories that they are working on in their reading classes to improve their fluency.

Students are excused from tutoring when they reach grade level on formal assessments given every quarter. In recent years, many SFA schools have been using Alphie's Alley, the computer-assisted, one-to-one tutoring program described in the following section, to support the tutoring of struggling readers.

\section{Computer-Assisted Tutoring: Alphie's Alley}

A key challenge for many SFA schools is that the amount and quality of tutoring is insufficient. Originally, SFA required certified teachers as tutors, but due to limitations on the availability of certified tutors as well as their cost, most schools have very few tutors; those tutors are usually paraprofessionals or volunteers. Even certified teachers can be challenged to adequately provide the individualized instruction required to bring struggling readers up to grade level. To deal with this issue, SFAF, in collaboration with CSLP, created Alphie's Alley to help tutors make effective use of individual tutoring sessions to help at-risk children make adequate progress in reading. Alphie's Alley is designed for use as a Tier II or Tier III intervention for struggling readers in an RTI framework. It assesses children and suggests individually tailored plans based on the assessments. It provides students with multimedia screens containing 12 types of activities designed to build skills such as phonemic awareness, sound blending, comprehension monitoring, and connected reading. The tutor has an active role in guiding the child, assessing ongoing progress, and modifying plans in light of the child's needs.

The computer also provides a performance support system for the tutor, including video clips showing expert tutors implementing each type of activity with chil- 
dren with various strengths and weaknesses (Gery, 2002). This professional development is intended to help tutors become more thoughtful and strategic in working with their at-risk students (Chambers, Abrami, McWhaw, \& Therrien, 2001).

In common with the Success for All beginning reading program, Alphie's Alley also incorporates brief (1-3 minute) embedded multimedia segments, including animations to introduce letter sounds, puppet skits to introduce sound blending, and live-action skits to introduce vocabulary (Baddeley, 2004; Hoeffler \& Leutner, 2006; Mayer, 2005, 2008; Verhallen, Bus, \& de Jong, 2006). Evaluations found that first graders who experienced the embedded multimedia content learned to read significantly better than those who received an identical curriculum lacking the multimedia content (Chambers, Cheung, Madden, Slavin, \& Gifford, 2006).

Alphie's Alley, combined with embedded multimedia used in the regular reading class, was evaluated in two year-long randomized controlled trials. In the first study (Chambers, Abrami, et al., 2008), tutors and 412 low-achieving first graders in 25 schools were randomly assigned to participate in tutoring with Alphie's Alley or the regular one-to-one SFA tutoring. On individually administered reading measures, controlling for pretests, the students with tutors who used Alphie's Alley and were rated as "fully implementing" scored significantly better on reading measures. These results suggest that if well implemented, technology that enhances the performance of tutors has promise in improving the reading performance of at-risk children.

The second study, a randomized experiment in two primarily Hispanic SFA schools, found very positive effects for the combined treatment of Alphie's Alley and in-class embedded multimedia for the reading achievement of low-achieving first graders who received tutoring (Chambers, Slavin, et al., 2008). Significant positive effects were found on the Woodcock Letter-Word and Word Attack scales and on the Gray Oral Reading Test Fluency and Comprehension scales, with a median effect size of 0.53 .

\section{Team Alphie: Small-Group, Computer-Assisted Tutoring}

Team Alphie was designed to create a small-group supplementary reading intervention for students reading up to third-grade level, closely linked to the core reading instruction of the SFA program. Team Alphie is designed as a Tier II intervention in an RTI framework; students who do not succeed in Team Alphie can receive Alphie's Alley or other one-to-one tutoring if the small-group intervention is not sufficient. Team Alphie combines cooperative learning, computer-assisted instruction, embedded multimedia, and tutoring. It incorporates elements of the one-to-one Alphie's Alley but is used with groups of students, usually six children, divided into similarability pairs, with each pair working on a computer.

Peer-assisted learning (or cooperative learning) refers to teaching methods in which pupils help one another learn academic content. Team Alphie uses pairlearning methods based on programs such as Peer-Assisted Learning Strategies (Fuchs, Fuchs, Mathes, \& Simmons, 1997; Mathes, Howard, Allen, \& Fuchs, 1998) and Classwide Peer Tutoring (Greenwood et al., 1987). Within groups of struggling readers, Team Alphie has pairs of pupils work together at a computer, taking turns as "reader" and "coach." The computer poses a question or a task, and after the reader has given an answer, the computer gives the correct answer and the coach indicates whether or not the reader's response matched the computer's. Research on peer- 
assisted learning strategies of this kind (though lacking computers) in early reading has found substantial positive effects on reading measures (Calhoon, Al Otaiba, Cihak, King, \& Avalos, 2007; Calhoon, Al Otaiba, Greenberg, King, \& Avalos, 2006; Greenwood et al., 1987; Mathes \& Babyak, 2001; Mathes et al., 1998, 2003). Slavin et al. (2010), summarizing outcomes for struggling readers in studies of peer-assisted learning methods, reported a sample-size weighted mean effect size of 0.58 on independent reading measures.

Team Alphie provides daily 45-minute lessons in phonemic awareness, phonics, fluency, vocabulary, and comprehension, with the focus on decoding and fluency skills. The program has three components_assessment, planning, and computer activities - with embedded professional development to support implementation.

Assessment. Team Alphie assesses children's reading strengths and difficulties in the areas of phonemic awareness, phonics, fluency, and comprehension. Like most RTI approaches, the program continuously updates information relevant to the students' progress.

Planning. The program presents a 2-week tutoring plan based on the lowest partner's assessment. At the end of the 2-week period, a new plan is generated based on the pair's performance on the activities.

Computer activities. Team Alphie uses the Alphie's Alley activities, adapted for use by two students, rather than a tutor and tutee. Students work on computer activities specifically designed to reinforce skills taught in their core reading program. In some activities, students have an opportunity to respond directly on the computer. If the student cannot produce a correct answer, the computer gives progressive scaffolding until the right answer is reached. In other activities, the student responds to his or her partner, who records whether the student's response was correct or not; if incorrect, the computer provides scaffolded support to help the child come to the right answer. Specific activities that students encounter are as follows:

1. Letter identification. The computer gives a sound, and the student must select a letter of letter combination that makes that sound.

2. Letter writing. Same as letter identification, except that the student must type or write the letter or letter combination.

3. Auditory blending. The computer presents sounds for two-, three-, or fourphoneme words, which the student blends into a word.

4. Auditory segmenting. The computer says a word and the student must break it into its separate sounds.

5. Sight words. The computer displays sight words, which the student reads.

6. Word-level blending. The computer displays a word and the student uses sound blending to decode it.

7. Spelling. The computer says a word and the student types it. At higher levels, the computer reads a sentence that the student types.

8. Story preparation. Before the child reads a decodable story, the computer displays story-related words (both phonetically regular and sight words) for the student to practice.

9. Tracking. Students read a decodable story book on the computer to their partners and use an arrow key to track word by word. The computer models appropriate 
decoding strategies if the student cannot decode a word, and orally presents sight words that the student does not know.

10. Fluency. Students read a decodable story to their partners, who note errors and times to compute words correct per minute. Fluency practice and assessment focuses on accuracy, then smoothness, then expression, then rate.

11. Comprehension questions. The computer displays questions about the stories that the students answers to their partners. These are prediction, summarization, and inferential questions and questions about story structure (e.g., characters, setting).

12. Graphic organizers. The students complete a graphic organizer to represent main ideas from the stories.

Performance support for tutors. Team Alphie facilitates assessment and record keeping, and provides performance support for tutors in the form of video vignettes and written suggestions on how to help remediate students' particular problems. Once a diagnosis has been made about students' specific problems, the tutor can view demonstrations of a variety of intervention strategies to help remediate that problem. For example, if a tutor determines that a child has a problem with visual tracking, then the tutor can view video vignettes of other tutors modeling ways to help children learn to track. Short audiovisual vignettes provide immediate expert guidance to the tutors focused on the exact problem they are confronting.

As pairs work on Team Alphie activities, the tutor monitors them, providing in-person instructional support and conducting quick assessments to verify students' mastery of objectives, which reflects the RTI approach to supporting struggling readers. When a pair masters an instructional objective, a green flag appears to inform the tutor that the students are ready for a quick assessment to verify each partner's mastery of the objective. If both partners pass the quick assessment administered by the tutor, Team Alphie presents the next level of objectives for that activity. However, if either partner fails to pass the quick assessment, Team Alphie continues presenting objectives at the current level. With each quick assessment, Team Alphie immediately processes the data for each pair and adjusts the pairs' instructional plans accordingly. Team Alphie does not allow a pair to move forward until both partners have mastered the objective at the assigned level.

If a pair does not make progress finishing its assigned Team Alphie activities, the program displays an orange flag as an indication that the tutor should spend extra time monitoring this pair. As part of this monitoring, one or both partners may need direct instruction in a specific skill or activity, or the tutor may need to address a behavioral issue. By monitoring the pairs, the tutor ensures that partners understand how to record answers correctly, evaluates whether the pairs are appropriately placed or grouped, and determines whether the instructional plan is inappropriate for the pair.

\section{The Present Study}

The present study evaluated the relative effects of computer-assisted tutoring in small groups (Team Alphie) and ordinary one-to-one tutoring provided to struggling readers in Success for All schools. If Team Alphie is as effective as one-to-one tutoring, it will be possible to extend tutoring to many more struggling readers than could otherwise be served. Such an outcome might provide further support for the 
findings of Chambers, Abrami, et al. (2008) and Chambers, Slavin, et al. (2008) to the effect that supplemental human tutoring with targeted technology can enhance the outcomes of tutoring for struggling readers.

\section{Study Questions}

Study questions were as follows: (1) What are the effects of small-group, computer-assisted tutoring in comparison to one-to-one tutoring on reading achievement for low-achieving first- and second-grade struggling readers? (2) How efficient is small-group, computer-assisted tutoring compared to traditional one-toone tutoring in terms of the numbers of children who can receive effective tutoring services?

\section{Method}

\section{Participants}

The study took place in 33 high-poverty SFA schools located in nine states: Georgia, Massachusetts, Texas, Washington, Oregon, Mississippi, Florida, Pennsylvania, and Colorado. All of the tutors were certified teachers, and there were the equivalent of two full-time tutors per school. These schools had majorities of minority students: the treatment schools on average were 64\% African American and 24\% Hispanic, and the control schools were 80\% African American and 14\% Hispanic. Only 5\% of the control students and $10 \%$ of the treatment students were Caucasian.

Because we only needed to identify potential struggling readers and to reduce the testing burden, the lowest 50\% of first and second graders were identified by each school as potentially eligible for tutoring. These students were pretested in the early fall on a standardized reading measure described below, and the lowest-scoring 20 students in both the first and second grades in each school were assigned to be eligible for tutoring. Entire schools were randomly assigned to implement either Team Alphie or regular (paper-and-pencil) SFA one-to-one tutoring for the 2007-2008 school year. As the number of students exceeded the availability of tutors, the lowest scorers on each list were selected first, and then as students either left the school or reached grade level, they were replaced by the next-lowest student on the list.

\section{Treatments}

Students in both conditions who experienced difficulties in reading were assigned to daily tutoring sessions. Each school provided two tutors to participate in the study. Tutors in both conditions received essentially the same day-long training, which provided an overview of the SFA tutoring program and went into details about the tutoring objectives, the assessment process, targeted planning, and communication between teacher and tutor to enhance students' reading instruction. For the last part of the training, Team Alphie tutors learned how to use the software while the paperand-pencil tutors practiced administering the paper-and-pencil assessments. The tutoring activities in both conditions covered the following skills: phonemic awareness, concepts about print, letter skills, sight words, vocabulary, tracking, fluency, comprehension, and writing. 


\section{Experimental Treatment: Team Alphie Small-Group, Computer-Assisted Tutoring}

In the experimental schools, students identified as being in need of tutoring were assigned to groups of six students, up to the number of groups that the two tutors participating in the study could accommodate. The students participated in Team Alphie at least four times a week with a tutor for 45-minute sessions, as described above in the section on Team Alphie. The tutor monitored the pairs as they worked on the computers and verified that students had mastered a level of the skill they were working on. When students reached the level of their reading class on the SFA quarterly assessments, they were excused from tutoring and the next child on the list replaced them in the Team Alphie sessions. Because these students were struggling beginning readers, most of the activities they worked on were related to phonics skills.

\section{Control Treatment}

In the control schools, students identified as being in need of tutoring were assigned to be tutored in the number of slots available for the two tutors participating in the study. Students were individually tutored for daily 20 -minute sessions, using the standard paper-and-pencil tutoring process, as described previously in the section on Success for All. When students reached the level of their reading class on the SFA quarterly assessments, they were excused from tutoring and the next child on the list replaced them in tutoring. The paper-and-pencil tutoring process included assessment, planning, and student activities that focused on the same objectives as those in the computer-assisted tutoring program. The use or nonuse of the smallgroup, computer-assisted tutoring program was the only factor differentiating experimental and control treatments.

\section{Measures}

Specially trained testers, unaware of the children's experimental assignments, administered reading scales from the Woodcock-Johnson III Tests of Achievement (Woodcock, McGrew, \& Mather, 2001). The Woodcock-Johnson III Tests of Achievement were normed on a national sample of children, and the test-retest coefficients for the two subtests used were .95 for Letter-Word Identification and .83 for Word Attack.

Woodcock Letter-Word Identification (pre, post). The Letter-Word Identification (LWID) scale of the Woodcock-Johnson III was used as a pretest and then as a posttest. The LWID scale requires subjects to identify isolated letters and words.

Woodcock Word Attack (post). The Word Attack (WA) scale asks subjects to read nonsense words as an assessment of phonetic skills.

Woodcock Passage Comprehension (post). The Passage Comprehension (PC) scale measures students' ability to study a short passage, usually two to three sentences long, and identify a key word missing from the passage. 


\section{Implementation Fidelity}

Trainers, whose job is evaluating the implementation quality of both the regular SFA tutoring and Team Alphie tutoring, conducted in-class observations and rated the quality of implementation of the Team Alphie program and the control SFA tutoring on a three-point scale: fully implementing, partially implementing, and poorly implementing. Trace data on the amount of time the program was used were collected by the software.

\section{Procedure}

After pretesting, the lowest-performing students were assigned to tutoring and were tutored until they reached the average reading level of their reading classes. They were then excused from tutoring. The next-lowest-scoring students took their place in tutoring. Some of the experimental schools ran out of children who were participating in the study, so other students were included in the tutoring groups. Study students were individually administered the LWID, WA, and PC scales at posttest in spring 2008.

\section{Analyses}

The data were first analyzed using a multivariate analysis of covariance (MANCOVA), examining all four dependent variables together and controlling for LWID on pretests. Analyses of covariance were then carried out for each dependent variable, also controlling for LWID. Effect sizes were computed as the difference between experimental and control individual student posttests after adjustment for pretests and other covariates, divided by the unadjusted posttest control-group standard deviation.

\section{Results}

Analysis of the pretest data indicated that students in the Team Alphie (experimental) schools scored significantly higher on the LWID than those in schools using regular one-to-one tutoring (control) in the first grade $(p<.05, E S=0.28)$ and marginally higher in the second grade $(p<.068, E S=0.21)$ (see Table 1 ).

Analyses of covariance (ANCOVAs) were conducted on posttests at the student level, separately by grade, with the LWID pretest score as the covariate (see Table 1 ). Analyses were carried out for the sample of students who participated in tutoring in either condition and were present for both pre- and posttests. The first-grade treatment group outperformed the individually tutored control group on all three covariate-adjusted dependent measures: $\operatorname{LWID}(E S=0.17, p=.05)$, WA $(E S=0.21$, $p=.04)$, and PC $(E S=0.15, p=.05)$. The second-grade treatment and individually tutored control groups showed no significant differences on any of the dependent measures. An important outcome of the study was that schools using Team Alphie were able to tutor $31 \%$ more first-grade students and $46 \%$ more second-grade students than the control schools. 
Table 1. Effect Sizes for Reading Outcomes for First and Second Graders by Condition

\begin{tabular}{|c|c|c|c|c|c|c|c|}
\hline & \multicolumn{4}{|c|}{ Pretest } & \multicolumn{3}{|c|}{ Covariate-Adjusted Posttest } \\
\hline & Mean & $S D$ & $p$ & ES & Mean & $p$ & ES \\
\hline \multicolumn{8}{|l|}{ First grade: } \\
\hline LWID & & & .005 & .28 & & .05 & .17 \\
\hline Treatment $(n=195)$ & 21.97 & 5.50 & & & 32.23 & & \\
\hline Control $(n=171)$ & 20.23 & 6.18 & & & 31.06 & & \\
\hline Word Attack & & & & & & .04 & .21 \\
\hline Treatment $(n=195)$ & & & & & 13.71 & & \\
\hline Control $(n=171)$ & & & & & 12.52 & & \\
\hline \multicolumn{8}{|l|}{ Passage } \\
\hline Comprehension & & & & & & .05 & .15 \\
\hline Treatment $(n=195)$ & & & & & 14.97 & & \\
\hline Control $(n=171)$ & & & & & 14.24 & & \\
\hline \multicolumn{8}{|l|}{ Second grade: } \\
\hline LWID & & & .068 & .21 & & .67 & -.03 \\
\hline Treatment $(n=177)$ & 33.08 & 5.84 & & & 38.73 & & \\
\hline Control $(n=103)$ & 31.68 & 6.70 & & & 38.94 & & \\
\hline Word Attack & & & & & & .64 & .05 \\
\hline Treatment $(n=177)$ & & & & & 16.18 & & \\
\hline Control $(n=103)$ & & & & & 15.88 & & \\
\hline \multicolumn{8}{|l|}{ Passage } \\
\hline Comprehension & & & & & & .17 & .01 \\
\hline Treatment $(n=177)$ & & & & & 18.94 & & \\
\hline Control $(n=103)$ & & & & & 18.45 & & \\
\hline
\end{tabular}

\section{Discussion}

The results of this randomized experiment demonstrate that the Team Alphie smallgroup, computer-assisted tutoring program significantly increased reading achievement (in comparison to one-to-one tutoring) for first graders and produced equal reading achievement for second graders. This is a notable finding, as there is a substantial body of evidence to support the notion that one-to-one tutoring is the most effective form of instruction. Because the Team Alphie classes were also able to tutor substantially greater numbers of children with equal or greater effects on the children who were tutored, the study results imply that Team Alphie can expand services for struggling readers. It may reduce the need for third-tier, one-to-one tutoring for some students.

The finding of this study, that the small-group, computer-assisted tutoring program was more effective for struggling first graders than one-to-one tutoring with a human tutor, runs counter to previous findings comparing individual and smallgroup tutoring and to research on computer-assisted instruction in reading (Slavin et al., 2010). There are a few unique characteristics of the Team Alphie intervention that might explain its effectiveness. The first is that the program is closely aligned with the core instruction that students receive in their reading classes, which is not common in CAI remedial interventions. That alignment may mean that the supplementary instruction better supports the children' learning.

Another characteristic of the program is the use of structured cooperative learning. Students work in similar-ability pairs on the computer. Partners support each other's learning by taking turns recording whether their partner's answers are correct or not and helping them when they can. Other pair-learning programs in which 
children take turns as teacher and learner have also been found to be effective in supporting children's literacy (e.g., Fuchs \& Fuchs, 2006; Mathes \& Babyak, 2001; Mathes et al., 1998).

Overall, first graders made more progress from pretest to posttest on Letter-Word Identification than second graders. It may be that the activities they were working on in Team Alphie focused more on the skills necessary for beginning reading than on the fluency and comprehension skills that the second graders needed. This is something for the developers to consider in further development of the program. In this study we only tested children who received tutoring in both conditions. Because the Team Alphie schools were able to tutor more children than the control school, if we had tested all the struggling readers-including those who did not receive tutoring - we speculate that the overall improvement in reading performance for the Team Alphie condition would have been higher than the control condition in both grades 1 and 2 .

One finding that is likely to be of great interest to schools wanting to implement an RTI approach was that Team Alphie schools were able to successfully serve one-third more first graders and close to one-half more second graders than the control schools. In tight financial times, when schools cannot afford to supply one-to-one tutoring for all students who need it, the option of having small-group, computerassisted tutoring that would allow them to reach more struggling readers would likely be welcome. Team Alphie was not only at least as effective as one-to-one tutoring for struggling second graders, and more effective for first graders, it was also a more efficient approach to the provision of support. Had Team Alphie only matched the performance of the one-to-one-tutored students (as was anticipated) it would likely be the better approach given the greater number of students helped. As a Tier II intervention, individual children who do not make sufficient progress in Team Alphie should receive one-to-one tutoring, but the evidence presented here suggests that the number of children who will need intensive services can be greatly reduced by the use of the program.

\section{Limitations}

One limitation of this randomized study was that there were significant pretest differences between the treatment and control students. These differences were controlled for in the posttest analyses, but this was an unfortunate randomization. Another issue was that there were not enough schools to conduct a school-level analysis even though the randomization was at the school level; therefore, the results understate the standard error, but to an unknown degree.

We decided to randomly assign schools to condition, rather than assign students within schools, for a number of reasons. First, school staffs were very happy to have the computer-assisted tutoring program, and the perception that some students were receiving better support than others may have created problems within schools. Second, assigning children to tutoring requires careful scheduling, and it would have been a difficult balance assigning children to different types of tutoring while keeping those separate within a school over the year.

There is a slight chance that the difference between the groups was due to the increased time in tutoring. However, this is unlikely because much of the additional time was spent in organizing the classes, logging in, getting the computers on the 
right activities, and verifying the pairs' progress, while in the one-to-one tutoring, tutoring began as soon as the child arrived at the session. Regarding the amount of tutor time each child received, in the one-to-one tutoring, each child received 20 minutes of the tutor's time per session; in the Team Alphie one-to-six sessions, each child received the equivalent of 7.5 minutes of the tutor's time per session.

There was variability in the amount of time that experimental schools used the program. The number of days that schools implemented the program over the year ranged from 22 to 84 . Some schools took a long time to get their computers and software up and running. Some did not devote sufficient time to implementing tutoring, with tutors being used as substitutes for absent teachers. However, despite these limitations, the students in the Team Alphie schools performed as well or better than the one-to-one tutoring schools.

\section{Conclusion}

In conclusion, the combination of computer-assisted tutoring, embedded multimedia, and cooperative learning in this reading intervention may indicate an effective and efficient way to help struggling students succeed in learning to read in the second tier of the Success for All RTI model. This approach to small-group remediation might provide a replicable solution for RTI models, which seek to keep struggling readers in general education classes with effective, targeted services.

\section{Note}

This research was funded by the Office of Elementary and Secondary Education at the U.S. Department of Education (grant no. S332B050004). However, any opinions expressed are those of the authors and do not necessarily represent the positions or policies of the funder. Correspondence concerning this article should be addressed to Bette Chambers, Center for Research and Reform in Education, Johns Hopkins University, 200 W. Towsontown Blvd., Baltimore, MD 21204, or bchambers@jhu.edu.

\section{References}

Abrami, P. C., Savage, R. S., Deleveaux, G., Wade, A., Meyer, E., \& Lebel, C. (2010). The Learning Toolkit: The design, development, testing and dissemination of evidence-based educational software. In P. Zemliansky \& D. M. Wilcox (Eds.), Design and implementation of educational games: Theoretical and practical perspectives (pp. 168-187). Hershey, PA: IGI Global.

Abrami, P. C., Savage, R., Wade, A., Hipps, G., \& Lopez, M. (2008). Using technology to assist children learning to read and write. In T. Willoughby \& E. Wood (Eds.), Children's learning in a digital world (pp. 129-172). Oxford: Blackwell.

Baddeley, A. D. (2004). The psychology of memory. In A. D. Baddeley, M. D. Kopelman, \& B. A. Wilson (Eds.), The essential handbook of memory disorders for clinicians (pp. 1-13). Chichester: Wiley.

$\rightarrow$ Borman, G. D., Hewes, G. M., Overman, L. T., \& Brown, S. (2003). Comprehensive school reform and achievement: A meta-analysis. Review of Educational Research, 73(2), 125-230.

$\rightarrow$ Borman, G. D., Slavin, R. E., Cheung, A., Chamberlain, A., Madden, N. A., \& Chambers, B. (2007). Final reading outcomes of the national randomized field trial of Success for All. American Educational Research Journal, 44(3), 701-731.

$\rightarrow$ Brown, K., Morris, D., \& Fields, M. (2005). Intervention after grade 1: Serving increased numbers of struggling readers effectively. Journal of Literacy Research, 37(1), 61-94. 
$\rightarrow$ Calhoon, M., Al Otaiba, S., Cihak, D., King, A., \& Avalos, A. (2007). The effects of a peer-mediated program on reading skill acquisition for two-way bilingual first-grade classrooms. Learning Disability Quarterly, 30(3), 169-184.

$\rightarrow$ Calhoon, M., Al Otaiba, S., Greenberg, D., King, A., \& Avalos, A. (2006). Improving reading skills in predominantly Hispanic Title I first grade classrooms: The promise of peer-assisted learning strategies. Learning Disabilities Research and Practice, 21(4), 261-272.

Campuzano, L., Dynarski, M., Agodini, R., \& Rall, K. (2009). Effectiveness of reading and mathematics software products: Findings from two student cohorts. Washington, DC: U.S. Department of Education.

$\rightarrow$ Chambers, B., Abrami, P., McWhaw, K., \& Therrien, M. C. (2001). Developing a computer-assisted tutoring program to help children at risk learn to read. In P. Abrami (Ed.), Understanding and promoting complex learning use technology. [Special issue on instructional technology]. Educational Research and Evaluation, 7(2/3), 223-239.

$\rightarrow$ Chambers, B., Abrami, P. C., Tucker, B. J., Slavin, R. E., Madden, N. A., Cheung, A., \& Gifford, R. (2008). Computer-assisted tutoring in Success for All: Reading outcomes for first graders. Journal of Research on Educational Effectiveness, 1(2), 120-137.

$\rightarrow$ Chambers, B., Cheung, A., Madden, N., Slavin, R. E., \& Gifford, R. (2006). Achievement effects of embedded multimedia in a Success for All reading program. Journal of Educational Psychology, 98(1), 232-237.

$\rightarrow$ Chambers, B., Slavin, R. E., Madden, N. A., Abrami, P. C., Tucker, B. J., Cheung, A., \& Gifford, R. (2008). Technology infusion in Success for All: Reading outcomes for first graders. Elementary School Journal, 109(1), 1-15.

Comprehensive School Reform Quality Center. (2006). CSRQ Center report on elementary school comprehensive school reform models. Washington, DC: American Institutes for Research.

Dynarski, M., Agodini, R., Heaviside, S., Novak, T., Carey, N., Campuzano, L., ... Sussex, W. (2007). Effectiveness of reading and mathematics software products: Findings from the first student cohort. Washington, DC: Institute of Education Sciences.

$\rightarrow$ Ehri, L., Dreyer, L., Flugman, B., \& Gross, Al. (2007). Reading Rescue: An effective tutoring intervention model for language-minority students who are struggling readers in first grade. American Educational Research Journal, 44(2), 414-448.

$\rightarrow$ Fuchs, D., \& Fuchs, L. S. (2006). Introduction to response to intervention: What, why, and how valid is it? Reading Research Quarterly, 41(1), 92-128.

$\rightarrow$ Fuchs, D., Fuchs, L., Mathes, G., \& Simmons, D. (1997). Peer-assisted learning strategies: Making classrooms more responsive to diversity. American Educational Research Journal, 34(1), 174206.

$\rightarrow$ Gery, G. (2002). Achieving performance and learning through performance centered systems. Advances in Developing Human Resources, 4(4), 464-478.

$\rightarrow$ Greenwood, C., Dinwiddie, G., Bailey, V., Carta, J., Dorsey, D., Kohler, F., . . Schulte, D. (1987). Field replication of classwide peer tutoring. Journal of Applied Behavior Analysis, 20, 151-160.

Hoeffler, T., \& Leutner, D. (2006, April). Instructional animation versus static picture: A metaanalysis. Poster presented at the annual meeting of the American Educational Research Association, San Francisco.

Klein, P. S., Nir-Gal, O., \& Darom, E. (2000). The use of computers in kindergarten, with and without adult mediation: Effects on children's cognitive performance and behavior. Computers in Human Behavior, 16(6), 591-608.

Kulik, J. A. (2003). Effects of using instructional technology in elementary and secondary schools: What controlled evaluation studies say (SRI Project No. P10446.oo1). Arlington, VA: SRI International.

$\rightarrow$ Mathes, P., \& Babyak, A. (2001). The effects of peer-assisted literacy strategies for first-grade readers with and without additional mini-skills lessons. Learning Disabilities Research \& Practice, 16(1), $28-44$.

$\rightarrow$ Mathes, P. G., Howard, J. K., Allen, S. H., \& Fuchs, D. (1998). Peer-assisted learning strategies for first-grade readers: Responding to the needs of diverse learners. Reading Research Quarterly, 33, 62-94.

$\rightarrow$ Mathes, P. G., Torgesen, J., Clancy-Menchetti, J., Santi, K., Nicholas, K., Robinson, C., \& Grek, M. (2003). A comparison of teacher-directed versus peer-assisted instruction to struggling firstgrade readers. Elementary School Journal, 103(5), 459-479. 
Mayer, R. E. (2005). Cognitive theory of multimedia learning. In R. E. Mayer (Ed.), The Cambridge handbook of multimedia learning (pp. 31-48). Cambridge: Cambridge University Press.

$\rightarrow$ Mayer, R. E. (2008). Applying the science of learning: Evidence-based principles for the design of multimedia learning. American Psychologist, 63(8), 760-769.

National Assessment of Educational Progress. (2007). The nation's report card. Washington, DC: National Center for Education Statistics.

$\rightarrow$ Savage, R., Abrami, P. C., Hipps, G., \& Deault, L. C. (2009). A randomized controlled trial study of the ABRACADABRA reading intervention program in grade 1. Journal of Educational Psychology, 101(3), 590-604.

$\rightarrow$ Slavin, R. E., Lake, C., Chambers, B., Cheung, A., \& Davis, S. (2009). Effective reading programs for the elementary grades: A best-evidence synthesis. Review of Educational Research, 79(4), 13911466.

Slavin, R. E., Lake, C., Davis, S., \& Madden, N. (2010). Effective programs for struggling readers: A best evidence synthesis. Educational Research Review. Retrieved from http://dx.doi.org/10.1016/ j.edurev.2010.07.002

Slavin, R. E., Madden, N. A., Chambers, B., \& Haxby, B. (2009). Two million children: Success for All. Thousand Oaks, CA: Corwin.

$\rightarrow$ Vaughn, S., Linan-Thompson, S., Kouzekanani, K., Bryant, D. P., Dickson, S., \& Blozis, S. A. (2003). Reading instruction groups for students with reading difficulties. Remedial and Special Education, 24(5), 301-315.

$\rightarrow$ Verhallen, M. J., Bus, A., \& de Jong, M. (2006). The promise of multimedia stories for kindergarten children at risk. Journal of Educational Psychology, 98(2), 410-419.

Woodcock, R. W., McGrew, K. S., \& Mather, N. (2001). Woodcock-Johnson III tests of achievement. Itasca, IL: Riverside. 